\title{
Femtosecond laser-assisted phototherapeutic keratectomy for the treatment of dense corneal scarring
}

\author{
Sloan W Rush ${ }^{1,2}$ and Ryan B Rush ${ }^{1,2,3}$ \\ ${ }^{1}$ Panhandle Eye Group, 7400 Fleming Ave., Amarillo, Texas 79106, USA \\ ${ }^{2}$ Texas Tech University Health Science Center, 1400 S. Coulter, Amarillo, Texas 79106, USA \\ ${ }^{3}$ Southwest Retina Specialists, 7411 Wallace Blvd., Amarillo, TX, 79106, USA
}

\begin{abstract}
Purpose: To report outcomes of a novel femtosecond laser-assisted phototherapeutic keratectomy (PTK) technique for the management of dense corneal scarring.

Methods: The charts of 4 consecutive subjects with dense anterior corneal scarring that underwent a femtosecond laser-assisted PTK protocol were retrospectively reviewed. The protocol consisted of removal of a femtosecond-created free cap lenticule according to a preoperative optical coherence tomography (OCT) depth of treatment calculation, followed by a hyperopic excimer laser ablation to achieve the desired refractive outcome. The main outcomes were change in best spectaclecorrected visual acuity (BSCVA) and change in corneal topography indices at three months after treatment.

Results: BSCVA improved from a mean of 2.13 [1.72-2.53] logMAR preoperatively to a mean of 1.35 [0.94-1.76] logMAR postoperatively (p=0.0170). None of the subjects experienced a loss of one or more lines of BSCVA after treatment. Corneal topography indices demonstrated improvement in corneal cylinder ( $\mathrm{p}=0.0276$ ) and surface asymmetry index $(\mathrm{p}=0.0203)$, but not in surface regularity index $(\mathrm{p}=0.3790)$ or projected visual acuity $(\mathrm{p}=0.3719)$. There were no intraoperative or postoperative complications associated with the treatment, and none of the subjects required additional treatment with either repeat PTK or with more invasive surgery such as lamellar or penetrating keratoplasty. Retinal disease limited the overall visual potential in all 4 subjects.

Conclusions: The femtosecond laser-assisted PTK technique described in this study may provide favorable visual and anatomic outcomes in subjects with dense corneal scarring that otherwise would have required lamellar or penetrating keratoplasty to restore the clarity of the ocular media.
\end{abstract}

\section{Introduction}

Many phototherapeutic keratectomy (PTK) techniques have been described for the management of corneal opacities localized to the anterior one-third of the corneal stroma [1-8]. However, a subgroup of patients with anterior corneal scarring are not able to undergo PTK because the corneal scarring is too dense (opaque) for the excimer laser system to track the pupil. Recent studies have established the role of optical coherence tomography (OCT) in determining the depth of corneal pathology and refining photoablation techniques in the setting of PTK [9-13]. The femtosecond laser has been effectively used for laser-assisted in situ keratomileusis (LASIK) [14], keratoplasty [15,16] and, more recently, cataract surgery [17] and refractive femtosecond lenticule extraction [18]. In this study, we report a novel OCT-guided technique which combines femtosecond lenticule extraction and PTK to treat dense anterior corneal scarring that otherwise would have required lamellar or penetrating keratoplasty to restore ocular media clarity.

\section{Methods}

The SRS Institutional Review Board (IORG0007600/IRB00009122) approved this retrospective chart review of consecutive patients that underwent OCT-guided femtosecond-assisted lenticule extraction combined with hyperopic excimer laser photoablation for treatment of dense corneal scarring from February 2014 through April 2014. All research components observed the statutes of the Declaration of Helsinki and were conducted in agreement with human subject research regulations and standards.

The inclusion criteria for the study were as follows: 1) the subject underwent OCT-guided femtosecond laser-assisted lenticule extraction combined with PTK for the treatment of a dense central opacity localized to the anterior one third of the corneal stroma, and 2) the subject was not a candidate for traditional PTK because corneal scarring was too dense for the excimer laser system to track the subject's pupil. Subjects were excluded from the study if follow-up was not documented out to 3 months following treatment.

Spectral domain OCT (Cirrus HD-OCT; Carl Zeiss Meditec, Inc, Dublin, California, USA) of the central $3 \mathrm{~mm}$ of the cornea was preoperatively assessed on all subjects. Multiple raster line scans in the vertical and horizontal meridians were centered over the apex of the cornea and the manual electronic caliper was used to obtain the following measurements: 1) maximum depth of the opacity, 2) baseline epithelial thickness (as ascertained from an area of the cornea that was void of scarring), and 3) total central corneal thickness. Only scans that

Correspondence to: Ryan Rush, MD, Southwest Retina Specialists, 7411 Wallace Blvd, Amarillo, TX, 79106, USA, Tel: (806) 351-1870; Fax: (806) 351-1690, E-mail: Ryanbradfordrush21@hotmail.com

Key words: femtosecond, phototherapeutic keratectomy, corneal scarring

Received: January 12, 2016; Accepted: January 25, 2016; Published: January 27, 2016 
had signal strength of 8 or greater and that were centered as determined by inspection of the scout view were selected for analysis.

\section{Femtosecond laser-assisted PTK treatment algorithm}

The treatment was initiated with off-label use of the WaveLight FS200 (Alcon, Fort Worth, TX, USA) femtosecond laser platform using the "Keratoplasty" mode to create a transepithelial free cap lenticule according to the following parameters: Top Diameter $8.5 \mathrm{~mm}$, Bed Cut Spot/Line Separation 4.0 microns/4.0 microns, Side Cut Spot/Line Separation 5.0 microns/2.0 microns, Pulse Energy for Bed and Side Cuts 1.45 microjoules, and Side Cut Angle 30 degrees. The depth of the lamellar cut varied for each patient according to the findings of the preoperative OCT. The OCT-measured maximum depth of the scar, which included the thickness of the corneal epithelium, was used as the primary target for depth of treatment. All femtosecond treatment depths were calculated to leave a residual stromal bed of at least 275 microns.

The femtosecond-cut free cap lenticule was removed and discarded, and the patient then underwent hyperopic excimer laser photoablation using the WaveLight EX500 (Alcon, Fort Worth, TX, USA). The hyperopic ablation profile was calculated in the following way: (total lamellar depth of tissue removed by the femtosecond laser in microns - depth of baseline epithelium thickness in microns) $\div 20+$ existing spherical equivalent in diopters = estimated total amount of induced hyperopia (in diopters) that must be accounted for by the ablation to achieve an emmetropic refractive result. This spherical hyperopic ablation treatment was used to return the patient back to a spherical equivalent at the desired refractive outcome so as to prevent large and visually-significant postoperative anisometropia. Highly myopic patients would not always require the secondary hyperopic ablation to achieve the desired postoperative refractive outcome.

\section{Preoperative routine, surgical technique and postoperative care}

Patients with known or suspected prior herpes simplex viral (HSV) keratitis were prophylactically given oral acyclovir $400 \mathrm{mg}$ twice daily one week prior to treatment. These patients were continued on acyclovir for a total of 3 months after the procedure.

Topical anesthetic and Betadine 5\% were applied to the ocular fornices. The femtosecond and excimer lasers were programmed to deliver two separate treatments as described above. The femtosecond treatment was delivered first. The patient was then positioned under the excimer laser where the corneal lamellar tissues bridges from the fresh femtosecond cut were separated using a blunt LASIK flap retractor. The free cap lenticule was discarded and the hyperopic excimer laser photoablation was performed (resulting in a delay of about 3 minutes between the femtosecond and excimer laser treatments). In all cases, mitomycin C $0.02 \%$ was applied to the stromal bed on an $8 \mathrm{~mm}$ diameter circular sponge for a total of 15 seconds followed by vigorous ocular surface irrigation with balanced salt solution after the excimer laser ablation. A bandage contact lens was placed on the cornea at the end of the treatment.

Topical ofloxacin $0.3 \%$ four times daily was used for one week and topical prednisolone acetate $1 \%$ was used four times daily for one week and twice daily for one week in the postoperative period. The bandage contact lens was removed 3-5 days after treatment. Patients were examined at 3-5 days, 2 weeks and 3 months postoperatively.

\section{Data collection and statistical analysis}

The best spectacle-corrected visual acuity (BSCVA), corneal topography (Tomey; Phoenix, AZ, USA) indices, and maximal crater depth on OCT were collected at baseline and follow-up examinations. The corneal topography indices measured included cylinder, projected visual acuity (PVA), surface asymmetry index (SAI), and surface regularity index (SRI). The JMP 11 software package from the SAS Institute (Cary, NC, USA) was used to perform statistical analysis. One way analysis of the variance compared baseline to postoperative outcomes. Results were considered statistically significant at the alpha $<0.05$ level.

\section{Results}

A total of 4 eyes of 4 patients were included in the analysis. The corneal scarring was due to chronic sterile corneal ulceration in two patients, HSV keratitis in one patient, and trauma in one patient. All 4 patients had an underlying retinal disease that limited Snellen BSCVA to $20 / 200$ or worse apart from the corneal scarring: two patients had advanced neovascular AMD and two patients had proliferative diabetic retinopathy with chronic macular edema. The mean subject age was $68.8(+/-8.8)$ years. The main outcomes are presented in Table 1. Excimer laser pupil tracking was successfully established in all cases after the femtosecond-cut free cap lenticule was removed. There were no intra-operative complications.

Postoperative corneal scarring on OCT resolved completely in all patients 3 months after treatment. One of the patients with proliferative diabetic retinopathy had delayed postoperative epithelial healing and underwent adjunctive treatment with autologous serum therapy to facilitate corneal re-epithelialization. None of the patients experienced the effects of aniseikonia postoperatively. None of the subjects required additional treatment with either repeat PTK or with more invasive surgery such as lamellar or penetrating keratoplasty (Figure 1-3).

\section{Discussion}

Techniques using the microkeratome and femtosecond laser to remove dense anterior corneal scarring have been described, and the femtosecond laser has demonstrated more predictable treatment depths with fewer corneal stromal bed irregularities compared to the microkeratome [19-21]. Our femtosecond laser-assisted PTK technique has many of the same theoretic advantages that transepithelial PTK has in restoring uniformity to Bowman's layer in eyes with corneal scarring associated with an irregular Bowman's layer $[13,22]$. Similar to conventional PTK, a hyperopic shift occurs following the

Table 1._Outcomes for Femtosecond Laser-assisted Phototherapeutic Keratectomy Using One-way Analysis of the Variance.

\begin{tabular}{|l|c|c|c|}
\hline Outcome Variable & $\begin{array}{c}\text { Preoperative } \\
\text { Means } \\
\text { [with 95\% CI] }\end{array}$ & $\begin{array}{c}\text { Postoperative } \\
\text { Means } \\
\text { [with 95\% CI] }\end{array}$ & p-value \\
\hline $\begin{array}{l}\text { Best spectacle-Corrected Visual } \\
\text { Acuity (LogMAR) }\end{array}$ & $2.13[1.72-2.53]$ & $1.35[0.94-1.76]$ & 0.0170 \\
\hline Topographic Cylinder (Diopters) & $8.37[5.65-11.08]$ & $3.83[1.11-6.54]$ & 0.0276 \\
\hline $\begin{array}{l}\text { Topographic Surface Asymmetry } \\
\text { Index }\end{array}$ & $7.03[5.37-8.69]$ & $4.03[2.36-5.69]$ & 0.0203 \\
\hline $\begin{array}{l}\text { Topographic Surface Regularity } \\
\text { Index }\end{array}$ & $2.40[1.86-2.94]$ & $2.10[1.56-2.64]$ & 0.3790 \\
\hline $\begin{array}{l}\text { Topographic Projected Visual } \\
\text { Acuity (LogMAR) }\end{array}$ & $0.53[0.39-0.66]$ & $0.45[0.32-0.58]$ & 0.3719 \\
\hline Corneal Scarring Depth (Microns) & $193[156-230]$ & $0[-37-37]$ & 0.0001 \\
\hline
\end{tabular}




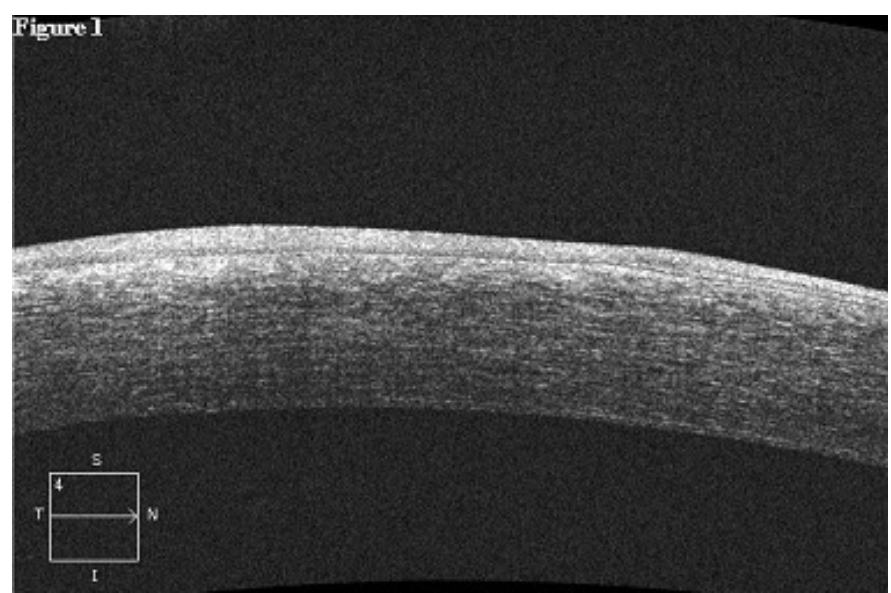

Figure 1. Femtosecond Laser-assisted Phototherapeutic Keratectomy for the Treatment of Dense Corneal Scarring. The preoperative corneal optical coherence tomography of a 71 year-old female demonstrates deep and dense central corneal scarring from a previous episode of herpes simplex viral keratitis. The total corneal thickness was measured at 628 microns, and the maximum depth of the corneal scar was measured at 192 microns. The best-spectacle corrected visual acuity was $20 / 800$.

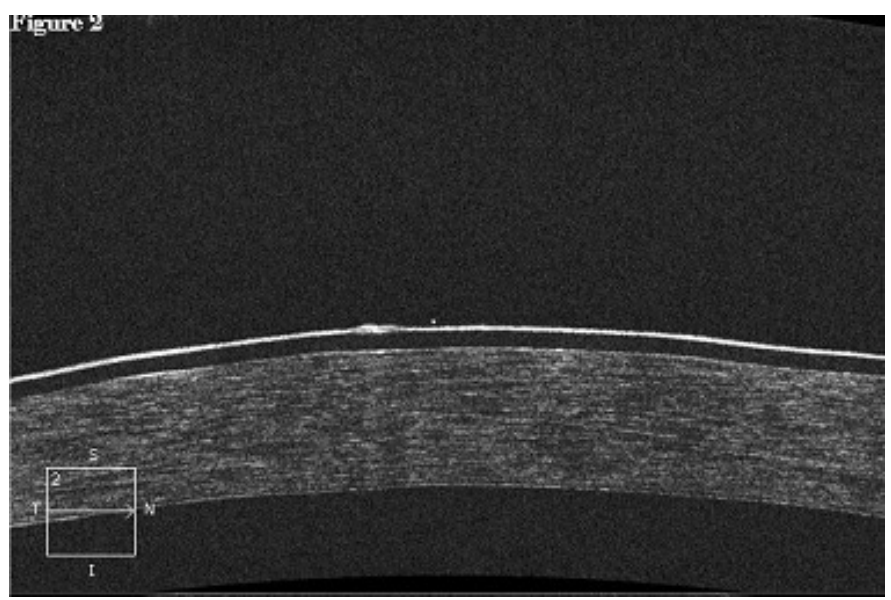

Figure 2. Femtosecond Laser-assisted Phototherapeutic Keratectomy for the Treatment of Dense Corneal Scarring. The corneal optical coherence tomography of the same patient in Figure 1 immediately after femtosecond laser-assisted phototherapeutic keratectomy demonstrates complete resolution of the corneal scar. The presence of a bandage contact lens and the absence of corneal epithelium is readily apparent. The residual stromal bed was measured at 476 microns (predicted of 428 microns) after removal of the 200 micron lenticule.

femtosecond laser portion of the algorithm described by this study [23]. The hyperopic excimer laser portion of our algorithm negates the effects of the induced hyperopia and reduces the risk of visuallysignificant postoperative anisometropia after lenticule removal. To our knowledge, this is the first study to perform PTK by means of OCTguided femtosecond laser lenticule extraction. The primary advantage of this technique over conventional PTK is that femtosecond laserassisted PTK is not limited by the excimer laser system's dependency on pupillary tracking. This makes our technique especially attractive in cases where corneal scarring is too dense for excimer laser pupillary tracking, and the patient is high risk for keratoplasty failure. In addition, femtosecond laser-assisted PTK can be performed at depths much greater than that of conventional PTK. The Wave Light EX500 maximum myopic ablation depth in one treatment is -10.00 sphere at an optic zone of $7.0 \mathrm{~mm}$, which is projected to ablate only 161 microns

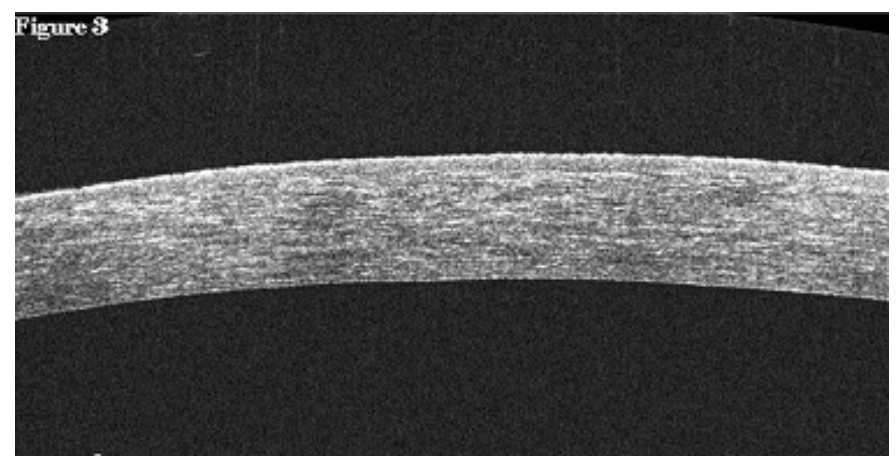

Figure 3. Femtosecond Laser-assisted Phototherapeutic Keratectomy for the Treatment of Dense Corneal Scarring. The corneal optical coherence tomography of the same patient in Figures 1-2 three months after femtosecond laser-assisted phototherapeutic keratectomy demonstrates marked improvement in the regularity of Bowman's layer and continued resolution of corneal scarring. Re-epithelialization has occurred and the total corneal thickness was measured at 452 microns. The best-spectacle corrected visual acuity improved to $20 / 200$, and the view to posterior pole was re-established to allow for ongoing treatment of exudative macular degeneration, which was limiting the patient's visual potential.

of central corneal tissue. However, corneal pathology is often found at a level deeper than 161 microns. Preoperative corneal OCT assessment can help clinicians determine which patients might benefit most from femtosecond laser-assisted PTK compared to conventional PTK.

Weaknesses of this study include the retrospective collection of data, the short follow-up interval, lack of a control group, and the small number of cases. In summary, the novel femtosecond laser-assisted PTK technique described in this study can provide favorable visual and anatomic outcomes in subjects with dense anterior corneal scarring that otherwise would require lamellar or penetrating keratoplasty. Our technique controls for postoperative refractive changes and lowers the likelihood of symptomatic anisometropia. Future controlled, prospective clinical trials are needed to further validate these results and determine the role that femtosecond laser-assisted PTK technique has on the management of eyes with dense corneal scarring.

\section{References}

1. Campos M, Nielsen S, Szerenyi K, Garbus JJ, McDonnell PJ (1993) Clinical follow-up of phototherapeutic keratectomy for treatment of corneal opacities. Am J Ophthalmol 115: 433-440. [Crossref]

2. Maloney RK, Thompson V, Ghiselli G, Durrie D, Waring GO $3^{\text {rd }}$, et al. (1996) A prospective multicenter trial of excimer laser phototherapeutic keratectomy for corneal vision loss (The Summit Phototherapeutic Keratectomy Study Group). Am J Ophthalmol 122: 149-160. [Crossref]

3. Kremer F, Aronsky M, Bowyer B, Stevens SX (2002) Treatment of corneal surface irregularities using biomask as an adjunct to excimer laser phototherapeutic keratectomy. Cornea 21: 28-32. [Crossref]

4. Hafner A, Seitz B, Langenbucher A, Naumann GO (2004) Phototherapeutic keratectomy (o-PTK) with $193 \mathrm{~nm}$ excimer laser for superficial corneal scars. Prospective long-term results of 31 consecutive operations. Ophthalmologe 101: 135-139. [Crossref]

5. Khoury JM, Salti H, El-Haibi C, Noureddin B (2009) Modified phototherapeutic keratectomy technique for the treatment of elevated corneal opacities. Ophthalmic Surg Lasers Imaging 40: 203-206. [Crossref]

6. Reinstein DZ, Archer TJ, Gobbe M (2013) Improved effectiveness of transepithelial PTK versus topography-guided ablation for stromal irregularities masked by epithelial compensation. J Refract Surg 29: 526-33. [Crossref]

7. Starr M, Donnenfeld E, Newton M, Tostanoski J, Muller J, et al. (1996) Excimer laser phototherapeutic keratectomy. Cornea 15 : 557-565.

8. Fagerholm P (2003) Phototherapeutic keratectomy: 12 years of experience. Acta Ophthalmol Scand 81: 19-32. [Crossref]

9. Mori H, Miura M, Iwasaki T, Goto H, Sakurai Y, et al. (2009) Three-dimensiona 
optical coherence tomography-guided phototherapeutic keratectomy for granular corneal dystrophy. Cornea 28: 944-947. [Crossref]

10. Ma JJ, Tseng SS, Yarascavitch BA (2009) Anterior segment optical coherence tomography for transepithelial phototherapeutic keratectomy in central corneal stromal scarring. Cornea 28: 927-929. [Crossref]

11. Ventura BV, Moraes HV Jr, Kara-Junior N, Marcony R Santhiago (2012) Role of optical coherence tomography on corneal surface laser ablation. J Ophthalmol 2012: 676740.

12. Cleary C, Li Y, Tang M, Samy El Gendy NM, Huang D (2014) Predicting transepithelial phototherapeutic keratectomy outcomes using fourier domain optical coherence tomography. Cornea 33: 280-287. [Crossref]

13. Rush SW, Matulich J, Rush RB (2014) Long-term outcomes of optical coherence tomography-guided transepithelial phototherapeutic keratectomy for the treatment of anterior corneal scarring. Br J Ophthalmol 98: 1702-1706. [Crossref]

14. Nordan LT, Slade SG, Baker RN, Suarez C, Juhasz T, et al. (2003) Femtosecond laser flap creation for laser in situ keratomileusis: six-month follow-up of initial U.S. clinical series. J Refract Surg 19: 8-14. [Crossref]

15. Chamberlain WD, Rush SW, Mathers WD, Cabezas M, Fraunfelder FW, et al. (2011) Comparison of femtosecond laser-assisted keratoplasty versus conventional penetrating keratoplasty. Ophthalmology 118: 486-491. [Crossref]

16. Rush SW, Fraunfelder FW, Mathers WD, Chamberlain WD (2011) Femtosecond laser- assisted keratoplasty in failed penetrating keratoplasty and globe trauma. Cornea. 30: 1358-1362. [Crossref]

17. He L, Sheehy K, Culbertson W (2011) Femtosecond laser-assisted cataract surgery. Curr Opin Ophthalmol 22: 43-52.

18. Kamiya K, Shimizu K, Igarashi A, Kobashi H (2014) Visual and refractive outcomes of femtosecond lenticule extraction and small-incision lenticule extraction for myopia Am J Ophthalmol 157: 128-134. [Crossref]

19. Alio JL, Javaloy J, Merayo J, Galal A (2004) Automated superficial lamellar keratectomy augmented by eximer laser masked PTK in the management of severe corneal opacities. Br J Ophthalmol 88: 1289-1294. [Crossref]

20. Alió JL, Agdeppa MC, Uceda-Montanes A (2011) Femtosecond laser-assisted superficial lamellar keratectomy for the treatment of superficial corneal leukomas. Cornea 30: 301-7. [Crossref]

21. Wilhelm FW, Giessmann T, Hanschke R, Duncker GI, Wilhelm LH (2000) Cut edges and surface characteristics produced by different microkeratomes. J Refract Surg 16 : 690-700. [Crossref]

22. Rush SW, Han DY, Rush RB (2013) Optical coherence tomography-guided transepithelial phototherapeutic keratectomy for the treatment of anterior corneal scarring. Am J Ophthalmol 156: 1088-1094. [Crossref]

23. Dogru M, Katakami C, Yamanaka A (2001) Refractive changes after excimer laser phototherapeutic keratectomy. J Cataract Refract Surg 27: 686-692. [Crossref]

Copyright: (C2016 Rush SW. This is an open-access article distributed under the terms of the Creative Commons Attribution License, which permits unrestricted use, distribution, and reproduction in any medium, provided the original author and source are credited. 